\title{
Eficácia ofensiva e variabilidade de padrões de jogo em futebol
}

CDD. 20.ed. 796.33

\section{Resumo}

0 presente estudo pretende caracterizar e comparar os padrões de jogo ofensivos realizados pelas equipes semifinalistas do Campeonato do Mundo FIFA 2010 - Espanha, Holanda, Alemanha e Uruguai. Através do instrumento de observação SoccerEye e do "software" de registo SoccerEye (v1.0, Março 2011), recolheramse 1938 sequências ofensivas de 28 jogos (sete por equipe) transmitidos por estações públicas de televisão. 0 instrumento de observação SoccerEye é constituído por sete critérios: 1) Início da fase ofensiva; 2) Desenvolvimento da Transição-Estado defesa/ataque; 3) Desenvolvimento da posse de bola; 4) Final da fase ofensiva; 5) Espacialização do terreno de jogo; 6) Centro do Jogo; e 7) Configuração Espacial de Interação. Para a análise sequencial dos dados utilizou-se o "software" SDIS-GSEQ (v5.0.77, 2010). Verificou-se que a seleção da Espanha, vencedora do Campeonato do Mundo FIFA 2010, tende a rematar à baliza adversária após passe curto positivo $(z=4,12)$ ou drible $(z=4,38)$, ambos os comportamentos realizados na zona central ofensiva $(z=3,94)$. A Espanha tende a marcar gols após uma ação do goleiro adversário $(z=5,95)$, que por sua vez resulta de um remate $(z=8,43)$ à baliza adversária. Conclui-se que a eficácia ofensiva das equipes semifinalistas no Campeonato do Mundo 2010 não se confina aos métodos e aos estilos de jogo utilizados, mas parece estar relacionada com a respetiva variação durante o mesmo jogo e/ou entre jogos diferentes, em resposta aos constrangimentos que o confronto com o adversário coloca.

PalAvRas-Chave: Padrão de jogo; Comportamento tático; Análise sequencial; Metodologia observacional; Análise de jogo.

\section{Introdução}

O jogo de Futebol afigura-se como sistema dinâmico no qual as equipes operam segundo distintos padrôes de ação ${ }^{1}$. Nesse sentido, envolve subsistemas e distintos níveis de organização que tendem a refletir padrões comportamentais observáveis na dinâmica do jogo.

$\mathrm{Na}$ literatura têm vindo a ser descritos modelos que visam o mapeamento do jogo de Futebol. Por exemplo, HEDERGOTT ${ }^{2}$ e TEODORESCU ${ }^{3}$ referem-se ao modelo de jogo dualista, que contempla duas fases: ofensiva e defensiva, diferenciadas pela existência ou não da posse de bola, respectivamente, enquanto Louis VAN GAal ${ }^{4}$, Oliveira ${ }^{5}$ e VelásQuez ${ }^{6}$ descrevem a organização do jogo com base em quatro momentos: a) organização ofensiva; b) transição ataque/defesa; c) organização defensiva; e d) transição defesa/ataque. Já Barreira e Garganta ${ }^{7}$, através do Modelo de organização do jogo de Futebol, perspectivam o jogo segundo duas fases (ofensiva e defensiva), que incluem e diferenciam os conceitos operacionais de transição, enquanto Estado e enquanto Interfase, conforme a recuperação da posse de bola aconteça de forma direta/ dinâmica ou indireta/estática, respectivamente.

MESQUiTA et al. ${ }^{8}$ consideram o ataque como a fase fundamental do jogo de Futebol, enquanto HugHES e BARTLETT ${ }^{9}$ se referem a este como um jogo de gols. Contudo, trata-se de uma modalidade que se distingue dos demais jogos desportivos coletivos pela reduzida quantidade de ataques que terminam com gol - $1 \%$ segundo Dufour ${ }^{10}$. Neste contexto, a criação de situaçōes de finalização através de remate à baliza adversária afiguram-se como comportamentos identificadores de eficácia no que respeita às sequências ofensivas.

A análise quantitativa de indicadores técnicos, tais como o número de passes, de gols marcados e/ou de 
cruzamentos, têm sido utilizados no estudo de equipes de sucesso em Campeonatos do Mundo ${ }^{11-16} \mathrm{e} \mathrm{em}$ Campeonatos Sul-Americanos de Futebol ${ }^{17}$. NEVILL et al. ${ }^{18}$ acrescentam a estes indicadores o remate $\mathrm{e}$ o tempo de posse de bola enquanto indicadores de performance que assumem elevada preponderância para se atingir o sucesso competitivo.

Não obstante, importa que na análise de comportamentos em Futebol se considere a variável ordem pois esta permite o conhecimento do diacronismo dos eventos e, por conseguinte, da lógica temporal do jogo ${ }^{19}$. Neste sentido, a metodologia observacional, e em particular a análise sequencial, têm sido utilizadas ${ }^{19-25}$, possibilitando uma análise quali-quantitativa, ordenada no tempo e em contexto natural, dos comportamentos dos jogadores e das equipes ${ }^{26}$.

\section{Método}

\section{Desenho experimental}

O desenho observacional de uma investigação empírica deverá estar intimamente associado aos objetivos do estudo. Neste sentido, a definição do desenho assume um papel central na metodologia observacional, na medida em que orienta o investigador na recolha, gestão e análise dos dados ${ }^{29}$.

A estrutura dos desenhos observacionais define-se a partir do cruzamento de três dimensões: as unidades observadas, a temporalidade e a dimensionalida$\mathrm{de}^{30}$. O desenho do presente estudo, de acordo com a taxonomia específica ${ }^{29}$, é nomotético (observam-se quatro equipes), de seguimento (registro contínuo ao longo dos jogos) e multidimensional (o instrumento de observação contempla sete critérios combinando formatos de campos com sistemas de categorias) no sentido de serem obtidas as sequências ofensivas.

\section{Amostra}

Registraram-se 1938 sequências ofensivas de 28 jogos do Campeonato do Mundo FIFA 2010, sete por equipe semifinalista (Alemanha, Espanha, Holanda e Uruguai), desde a fase de grupos até à jornada final do "play-off". Destes, consideraram-se os ataques eficazes $(n=273)$, i.e. que culminaram com remate à baliza adversária resultando em perda da
No presente estudo, tendo por base o modelo proposto por BARREIRA e GARGANTA ${ }^{7}$, e atendendo à fase ofensiva do jogo de Futebol, procura-se conhecer os padrões ofensivos eficazes das equipes de sucesso do Campeonato do Mundo 2010, caracterizandoos e comparando-os. Assim, pretende-se identificar método(s) ou estilo(s) de jogo que induzem eficácia ofensiva em equipes de sucesso. Entende-se por "equipes de sucesso" todas as que atingem as meias-finais de uma competição, de acordo com Grant et al. ${ }^{11} \mathrm{e}$ HugHes et al. ${ }^{27}$. Através do conhecimento da estrutura temporal dos padrões ofensivos eficazes no Futebol de elite ${ }^{28}$ pretende-se que treinadores, preparadores, e outros intervenientes no processo de treino influenciem a prática, no sentido de buscar maior congruência entre os princípios de jogo a adotar, a preparação/treino para jogar e o jogo propriamente dito.

posse de bola, de acordo com a seguinte distribuição: a) Alemanha: 61; b) Espanha: 84; c) Holanda: 67; e d) Uruguai: 61 .

\section{Instrumentos}

\section{Instrumento de observação}

Recorreu-se ao instrumento de observação SoccerEye ${ }^{31}$, constituído por sete critérios que combinam formatos de campo com sistemas de categorias e que permitem, de acordo com ANGUERA ${ }^{32}$, responder simultaneamente a um marco teórico e às particularidades do estudo. Os critérios são: 1) início da fase ofensiva/recuperação da posse de bola; 2) desenvolvimento da transição-estado defesa/ataque; 3) desenvolvimento da posse de bola; 4) final da fase ofensiva, através de quatro categorias identificadoras de ataques eficazes: a) remate não enquadrado com a baliza adversária (Frf); b) remate enquadrado com a baliza adversária (Frd); c) Remate interceptado, sem manutenção da posse de bola (Frad), e d) obtenção de gol (Fgl). Todas as sequências ofensivas que não terminem com remate são consideradas não-eficazes; 5) espacialização do terreno de jogo (FIGURA 1); 6) centro do jogo; e 7) configuração espacial de interação. São distribuídas pelos critérios 80 categorias exaustivas e mutuamente excludentes (TABELA 1). 


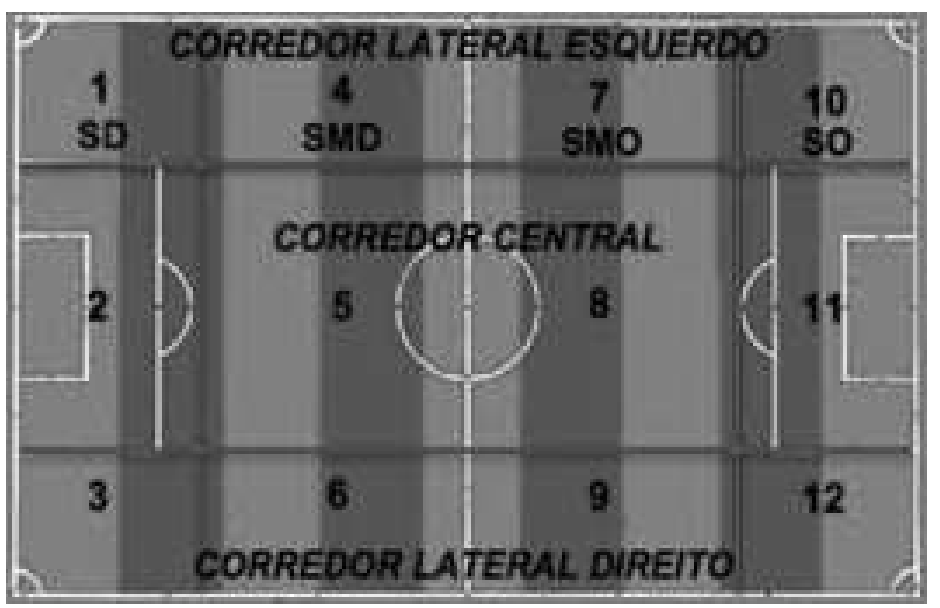

SD: setor defensivo; SMD: setor médiodefensivo; SMO: setor médioofensivo; SO: setor ofensivo.

FIGURA 1 - Espacialização do terreno de jogo dividido em 12 zonas $^{20}$.

Os quatro primeiros critérios representam os comportamentos realizados pelos jogadores em fase ofensiva, enquanto o quinto critério reflete uma divisão do terreno de jogo em 12 zonas $^{20,21}$. Já o sexto critério - Centro do Jogo (CJ) - define-se segundo BARREIRA e GARGANTA ${ }^{7}$ como o contexto de cooperação e de oposição entre os jogadores que participam ou estão em condiçôes de participar no jogo na zona onde se encontra a bola num determinado instante. Assim, a configuração no Centro do Jogo não se cinge a uma medida física (e.g. tempo, distância) mas baseia-se na avaliação comportamental dos intervenientes no jogo. Já o sétimo critério representa o Contexto Espacial de Interação ${ }^{22}$, que representa a relação entre o espaço de jogo efetivo - superfície que envolve todos os jogadores que se encontram nas partes exteriores da equipe num determinado instante ${ }^{33}$ - das duas equipes em confronto.

\section{Instrumento de registro}

O "software" de registo SoccerEye (versão 1.0, Março 2011) $)^{34}$ permite, simultaneamente, a visualização e o registo das açóes. É congruente com as categorias do instrumento de observação e com a linguagem do "software" de análise SDIS-GSEQ ${ }^{35}$. As diretrizes e definições que orientam o seu uso encontram-se descritas num Manual de Utilização, contemplando um sistema de precedências que conduzem o observador a uma acessível e fiável recolha dos dados.

\section{Procedimentos}

Registraram-se as sequências ofensivas durante o tempo regulamentar (90 min), com exceção dos ataques sem completa observação e/ou realizados sem que estivessem a jogar 11 jogadores por equipe.

\section{Qualidade dos dados}

A qualidade dos dados do estudo foi aferida através da fiabilidade intra-observador, com o recurso ao valor de Kappa de Cohen ${ }^{36}$, tendo o mesmo observador registrado a primeira parte da final do Mundial 2010 (Holanda "versus" Espanha) por duas vezes, com um intervalo de 15 dias. Com o recurso ao "software" SDISGSEQ obtiveram-se valores $0,91<\kappa<0,96$, com o menor valor $(\kappa=0,91)$ para o critério 6 : centro do jogo, e o maior para o critério 4: espacialização do terreno de jogo $(\kappa=0,96)$. Por serem superiores ao valor de $\kappa(\geq$ $0,75)$ sugerido por BAKEMAN e GOTTMAN ${ }^{37}$, os dados do presente estudo podem ser considerados fiáveis.

\section{Análise dos dados}

A análise sequencial de retardos permite indagar a existência de estabilidade na sucessão de comportamentos acima das probabilidades que são concedidas pelo acaso ${ }^{26}$. Através da eleição de uma conduta como critério, contabilizam-se as vezes que uma determinada conduta, assumida como objeto, a sucede retrospectiva ou prospectivamente, configurando-se o padrão de conduta (max-lag) ${ }^{38}$.

Com o recurso ao "software" SDIS-GSEQ (v5.0.77, 2010) ${ }^{35}$, optou-se por uma análise retrospectiva das 10 condutas prévias ao final do ataque, assumindo-se as categorias indicadoras de eficácia ofensiva (critério 4) como condutas critério. $\mathrm{O}$ valor $\mathrm{z}$-score $(\mathrm{z} \geq 1,96$, $\mathrm{p} \leq 0,05)$ determina o nível de significância entre as condutas, encontrando-se desta forma os padrōes ofensivos que tendem a ser realizados pelas equipes semifinalistas do Campeonato do Mundo FIFA 2010.

As regras convencionais de SACKETT $^{39}$ utilizadas para determinar o retardo máximo não foram aplicadas. 
TABELA 1 - Instrumento de observação SoccerEye ${ }^{31}$.

\begin{tabular}{|c|c|c|c|c|c|c|}
\hline $\begin{array}{l}\text { CRITÉRIO } 1 \\
\text { Início da Fase } \\
\text { Ofensiva/ } \\
\text { Recuperaçáo da } \\
\text { Posse de Bola } \\
\text { (BR) }\end{array}$ & $\begin{array}{c}\text { CRITÉRIO 2 } \\
\text { Desenvolvimento } \\
\text { da Transiçãa- } \\
\text { Estado defesa/ } \\
\text { ataque (DT) }\end{array}$ & $\begin{array}{l}\text { CRITÉRIO } 3 \\
\text { Desenvolvimento } \\
\text { da Posse de Bola } \\
\text { (DP) }\end{array}$ & $\begin{array}{l}\text { CRITÉRIO 4 } \\
\text { Final da Fase } \\
\text { Ofensiva (F) }\end{array}$ & $\begin{array}{l}\text { CRITÉRIO } 5 \\
\text { Espacialização do } \\
\text { terreno de jogo }\end{array}$ & $\begin{array}{l}\text { CRITÉRIO 6 } \\
\text { Centro do Jogo } \\
\text { (CJ) }\end{array}$ & $\begin{array}{l}\text { CRITÉRIO } 7 \\
\text { Contexto Espacial } \\
\text { de Interação } \\
\text { (CEI) }\end{array}$ \\
\hline $\begin{array}{l}\text { RECUPERAÇÁOO } \\
\text { DIRETA }\end{array}$ & $\begin{array}{c}\text { Passe curto } \\
\text { positivo (DTpcp) }\end{array}$ & $\begin{array}{c}\text { Passe curto } \\
\text { positivo (DPpcp) }\end{array}$ & COM EFICÁCIA & Zona um (1) & $\begin{array}{c}\text { COM } \\
\text { PRESSÃO (P) }\end{array}$ & $\begin{array}{c}\text { Goleiro da equipe } \\
\text { em fase ofensiva } \\
\text { versus linha } \\
\text { adiantada da } \\
\text { equipe adversária } \\
\text { (ADV) }\end{array}$ \\
\hline $\begin{array}{l}\text { Interceção (IEi) } \\
\text { Desarme (IEd) }\end{array}$ & $\begin{array}{c}\text { Passe curto } \\
\text { negativo (DTpcn) }\end{array}$ & $\begin{array}{c}\text { Passe curto } \\
\text { negativo (DPpcn) }\end{array}$ & $\begin{array}{c}\text { Remate não } \\
\text { enquadrado com } \\
\text { a baliza adversária } \\
\text { (Frf) }\end{array}$ & Zona dois (2) & $\begin{array}{l}\text { Inferioridade } \\
\text { relativa }(\mathrm{Pr})\end{array}$ & $\begin{array}{l}\text { Linha atrasada } \\
\text { versus linha } \\
\text { adiantada a } \\
\text { (ATAD) }\end{array}$ \\
\hline $\begin{array}{l}\text { Açáo do goleiro } \\
\text { em fase defensiva } \\
\text { (IEgr) }\end{array}$ & $\begin{array}{c}\text { Passe longo } \\
\text { positivo (DTplp) }\end{array}$ & $\begin{array}{c}\text { Passe longo } \\
\text { positivo (DPplp) }\end{array}$ & $\begin{array}{c}\text { Remate } \\
\text { enquadrado com } \\
\text { a baliza adversária } \\
\text { (Frd) }\end{array}$ & Zona três (3) & $\begin{array}{l}\text { Inferioridade } \\
\text { absoluta (Pa) }\end{array}$ & $\begin{array}{l}\text { Linha atrasada } \\
\text { versus linha } \\
\text { média (ATM) }\end{array}$ \\
\hline $\begin{array}{l}\text { Açấo defensiva } \\
\text { seguida de passe } \\
\text { (IEp) }\end{array}$ & $\begin{array}{c}\text { Passe longo } \\
\text { negativo (DTpln) }\end{array}$ & $\begin{array}{c}\text { Passe longo } \\
\text { negativo (DPpln) }\end{array}$ & $\begin{array}{c}\text { Remate } \\
\text { interceptado, } \\
\text { sem manutençâo } \\
\text { da posse de bola } \\
\text { (Frad) }\end{array}$ & Zona quatro (4) & $\begin{array}{c}\text { Igualdade } \\
\text { pressionada (Pi) }\end{array}$ & $\begin{array}{l}\text { Linha atrasada } \\
\text { versus zona } \\
\text { exterior (ATE) }\end{array}$ \\
\hline $\begin{array}{l}\text { RECUPERAÇÃOO } \\
\text { INDIRETA }\end{array}$ & $\begin{array}{c}\text { Cruzamento } \\
\text { positivo (DTczp) }\end{array}$ & $\begin{array}{c}\text { Cruzamento } \\
\text { positivo (DPczp) }\end{array}$ & $\begin{array}{l}\text { Obtençáo de gol } \\
\text { (Fgl) }\end{array}$ & Zona cinco (5) & SEM PRESSÃO & $\begin{array}{l}\text { Linha média } \\
\text { versus linha } \\
\text { adiantada } \\
\text { (MAD) }\end{array}$ \\
\hline $\begin{array}{l}\text { Começo/ } \\
\text { Recomeço do } \\
\text { jogo } \\
\text { (IIcg) }\end{array}$ & $\begin{array}{c}\text { Cruzamento } \\
\text { negativo (DTczn) }\end{array}$ & $\begin{array}{c}\text { Cruzamento } \\
\text { negativo (DPczn) }\end{array}$ & SEM EFICÁCIA & Zona seis (6) & $\begin{array}{l}\text { Igualdade não } \\
\text { pressionada (SPi) }\end{array}$ & $\begin{array}{l}\text { Linha média } \\
\text { versus linha } \\
\text { média }(\mathrm{MM})\end{array}$ \\
\hline $\begin{array}{c}\text { Infraçáo do } \\
\text { adversário às leis } \\
\text { do jogo (IIi) }\end{array}$ & $\begin{array}{l}\text { Condução de } \\
\text { bola (DTcd) }\end{array}$ & $\begin{array}{l}\text { Condução de } \\
\text { bola (DPcd) }\end{array}$ & $\begin{array}{l}\text { Erro do portador } \\
\text { da bola/açáo do } \\
\text { defesa adversário } \\
\text { (exceçāo para o } \\
\text { goleiro) (Fbad) }\end{array}$ & Zona sete (7) & $\begin{array}{l}\text { Superioridade } \\
\text { relativa (SPR) }\end{array}$ & $\begin{array}{l}\text { Linha média } \\
\text { versus linha } \\
\text { atrasada (MAT) }\end{array}$ \\
\hline $\begin{array}{l}\text { Pontapé de canto } \\
\text { cedido pelo } \\
\text { adversário (IIc) }\end{array}$ & $\begin{array}{l}\text { Drible (1x1) } \\
\text { (DTd) }\end{array}$ & $\begin{array}{l}\text { Drible }(1 \mathrm{x} 1) \\
\quad(\mathrm{DPd})\end{array}$ & $\begin{array}{l}\text { Açáo do goleiro } \\
\text { adversário (Fgrad) }\end{array}$ & Zona oito (8) & $\begin{array}{l}\text { Superioridade } \\
\text { absoluta (SPA) }\end{array}$ & $\begin{array}{l}\text { Linha adiantada } \\
\text { versus linha } \\
\text { média (ADM) }\end{array}$ \\
\hline $\begin{array}{l}\text { Pontapé de baliza } \\
\text { cedido pelo } \\
\text { adversário (IIpb) }\end{array}$ & $\begin{array}{c}\text { Recepção/ } \\
\text { controle (DTrc) }\end{array}$ & $\begin{array}{c}\text { Recepção/ } \\
\text { controle (DPrc) }\end{array}$ & $\begin{array}{l}\text { Lançamento da } \\
\text { bola para fora } \\
\text { (Ff) }\end{array}$ & Zona nove (9) & & $\begin{array}{l}\text { Linha adiantada } \\
\text { versus linha } \\
\text { atrasada (ADAT) }\end{array}$ \\
\hline $\begin{array}{l}\text { Bola ao solo } \\
\quad \text { (IIbs) }\end{array}$ & Duelo (DTdu) & Duelo (DPdu) & $\begin{array}{l}\text { Infraçáo às leis de } \\
\text { jogo }(\mathrm{Fi})\end{array}$ & Zona dez (10) & & $\begin{array}{l}\text { Zona exterior da } \\
\text { linha adiantada } \\
\text { versus linha } \\
\text { atrasada (EAT) }\end{array}$ \\
\hline \multirow[t]{2}{*}{$\begin{array}{c}\text { Lançamento } \\
\text { de linha lateral } \\
\text { cedido pelo } \\
\text { adversário (IILL) }\end{array}$} & Remate (DTr) & Remate (DPr) & & Zona onze (11) & & $\begin{array}{c}\text { Linha adiantada } \\
\text { versus goleiro da } \\
\text { equipe adversária. } \\
\text { (ADV) }\end{array}$ \\
\hline & $\begin{array}{l}\text { Intervençáo do } \\
\text { adversário sem } \\
\text { êxito (DTse) }\end{array}$ & $\begin{array}{l}\text { Intervenção do } \\
\text { adversário sem } \\
\text { êxito (DPse) }\end{array}$ & & Zona doze (12) & & \\
\hline
\end{tabular}

continua

670 • Rev Bras Educ Fís Esporte, (São Paulo) 2013 Out-Dez; 27(4):667-77 
TABELA 1 - Instrumento de observação SoccerEye ${ }^{31}$ (continuação).

\begin{tabular}{|c|c|c|c|c|c|c|}
\hline \multirow[t]{8}{*}{$\begin{array}{l}\text { CRITÉRIO } 1 \\
\text { Início da Fase } \\
\text { Ofensiva/ } \\
\text { Recuperaçáo da } \\
\text { Posse de Bola } \\
\text { (BR) }\end{array}$} & $\begin{array}{c}\text { CRITÉRIO 2 } \\
\text { Desenvolvimento } \\
\text { da Transição- } \\
\text { Estado defesa/ } \\
\text { ataque (DT) }\end{array}$ & $\begin{array}{l}\text { CRITÉRIO 3 } \\
\text { Desenvolvimento } \\
\text { da Posse de Bola } \\
\text { (DP) }\end{array}$ & $\begin{array}{c}\text { CRITÉRIO } 4 \\
\text { Final da Fase } \\
\text { Ofensiva (F) }\end{array}$ & $\begin{array}{l}\text { CRITÉRIO 5 } \\
\text { Espacializaçáo do } \\
\text { terreno de jogo }\end{array}$ & $\begin{array}{c}\text { CRITÉRIO 6 } \\
\text { Centro do Jogo } \\
\text { (CJ) }\end{array}$ & $\begin{array}{l}\text { CRITÉRIO } 7 \\
\text { Contexto Espacial } \\
\text { de Interaçáo } \\
\text { (CEI) }\end{array}$ \\
\hline & $\begin{array}{l}\text { Açáa do goleiro } \\
\text { da equipe em fase } \\
\text { ofensiva (DTgro) }\end{array}$ & $\begin{array}{l}\text { Açáo do goleiro } \\
\text { da equipe em fase } \\
\text { ofensiva (DPgro) }\end{array}$ & & & & \\
\hline & $\begin{array}{l}\text { Ação do goleiro } \\
\text { da equipe em } \\
\text { fase defensiva } \\
\text { (DTgra) }\end{array}$ & $\begin{array}{l}\text { Ação do goleiro } \\
\text { da equipe em fase } \\
\text { defensiva (DPgra) }\end{array}$ & & & & \\
\hline & & $\begin{array}{l}\text { Infraçāo do } \\
\text { adversário às leis } \\
\text { de jogo (DPi) }\end{array}$ & & & & \\
\hline & & $\begin{array}{l}\text { Pontapé de canto } \\
\text { (DPc) }\end{array}$ & & & & \\
\hline & & $\begin{array}{c}\text { Pontapé de baliza } \\
\text { (DPpb) }\end{array}$ & & & & \\
\hline & & $\begin{array}{l}\text { Bola ao solo } \\
\text { (DPbs) }\end{array}$ & & & & \\
\hline & & $\begin{array}{l}\text { Lançamento } \\
\text { de linha lateral } \\
\text { (DPLL) }\end{array}$ & & & & \\
\hline
\end{tabular}

\section{Resultados}

Os resultados do estudo encontram-se descritos e organizados de acordo com os padrōes ofensivos encontrados para cada uma das categorias identificadoras de ataques eficazes (critério 4, TABELA 1) .

Na FIGURA 2A é possível observar o padrão ofensivo da Alemanha correspondente ao final de ataque com remate não enquadrado a baliza adversária (Frf), i.e. que não atinge a baliza e sai pela linha de baliza adversária. Este tipo de remate apresenta elevada probabilidade de ocorrer após passe curto $(\mathrm{z}=4,04)$ na zona central médio-ofensiva $(\mathrm{z}=2,29)$, com a bola em posse da linha adiantada da equipe observada e a linha atrasada da equipe adversária $(z=3,79)$.

Já na seleção de Espanha, o remate não enquadrado com a baliza adversária tende a resultar de um cruzamento $(z=6,20)$ na zona lateral direita ofensiva $(\mathrm{z}=3,17)$ ou de um passe curto $(\mathrm{z}=4,52)$ na zona central ofensiva $(\mathrm{z}=3,59)$, ambos resultantes de situações de $1 \mathrm{x} 1(\mathrm{z}=2,58)$ em desenvolvimento da posse de bola. Já na FIGURA 2B é possível observar que a seleção da Holanda tende igualmente a utilizar situações de $1 \mathrm{x} 1(\mathrm{z}=2,76)$, assim como duelos $(\mathrm{z}$ $=5,85)$, ambos os comportamentos indutores de remates não enquadrados com a baliza adversária, e que tendem a ser precedidos por infraçôes do adversário às leis do jogo $(\mathrm{z}=3,36)$ nas zonas central médio-ofensiva $(\mathrm{z}=2,66)$ e ofensiva $(\mathrm{z}=3,98)$.

Contrariamente ao observado nas equipes da Alemanha, Espanha e Holanda, o padrão ofensivo relativo a remate não enquadrado a baliza adversária da seleção do Uruguai evidencia a utilização de comportamentos em Transição-Estado defesa/ataque, em que o remate provavelmente ocorreu após uma recepção/ controle da bola $(z=5,67)$ na zona central ofensiva $(z=7,09)$, em contextos de interação favoráveis (SPi: $\mathrm{z}=2,91$; ADAT: $\mathrm{z}=4,10$, consultar TABELA 1 ). Verifica-se assim que as equipes semifinalistas do Campeonato do Mundo FIFA 2010, com exceção do Uruguai, tendem a utilizar comportamentos em desenvolvimento da posse de bola para concluir o ataque através de remate que não atinge a baliza e sai pela linha de baliza adversária.

O remate enquadrado com a baliza adversária (Frd), i.e. que atinge a baliza adversária sem que seja obtido gol, tende a realizar-se na zona central ofensiva - 11 - na maioria das equipes semifinalistas (Alemanha: $\mathrm{z}=2,87$; Espanha: $\mathrm{z}=3,82$; Holanda: $\mathrm{z}$ $=3,60)$. O Uruguai, por sua vez, não revela qualquer 
Consultar o instrumento de observação SoccerEye (TABELA1). zona do terreno de jogo significativamente associada a esta ação de finalização. Em todas as equipes o remate é precedido por comportamentos na mesma zona em que é realizado (zona 11): condução de bola na Alemanha $(z=4,35)$, drible e passe curto na Espanha ( $\mathrm{z}=4,38$ e $\mathrm{z}=4,12$, respetivamente), e passe curto nas seleções da Holanda e Uruguai (z $=4,52$ e $\mathrm{z}=3,54$, respetivamente).

$\mathrm{O}$ remate enquadrado com a baliza adversária na equipe da Alemanha ocorre em contexto de confronto entre a sua linha adiantada e a linha defensiva do adversário $(\mathrm{z}=2,32)$, sendo precedidos por passe curto positivo $(\mathrm{z}=2,31)$ em contexto de linha adiantada "versus" goleiro adversário $(\mathrm{z}=4,74)$, resultante de cruzamento positivo $(\mathrm{z}=3,96)$ ou de drible $(z=3,36)$ em Transição-Estado defesa/ataque.

Já a Espanha, no momento do remate enquadrado com a baliza adversária, cria uma situação de
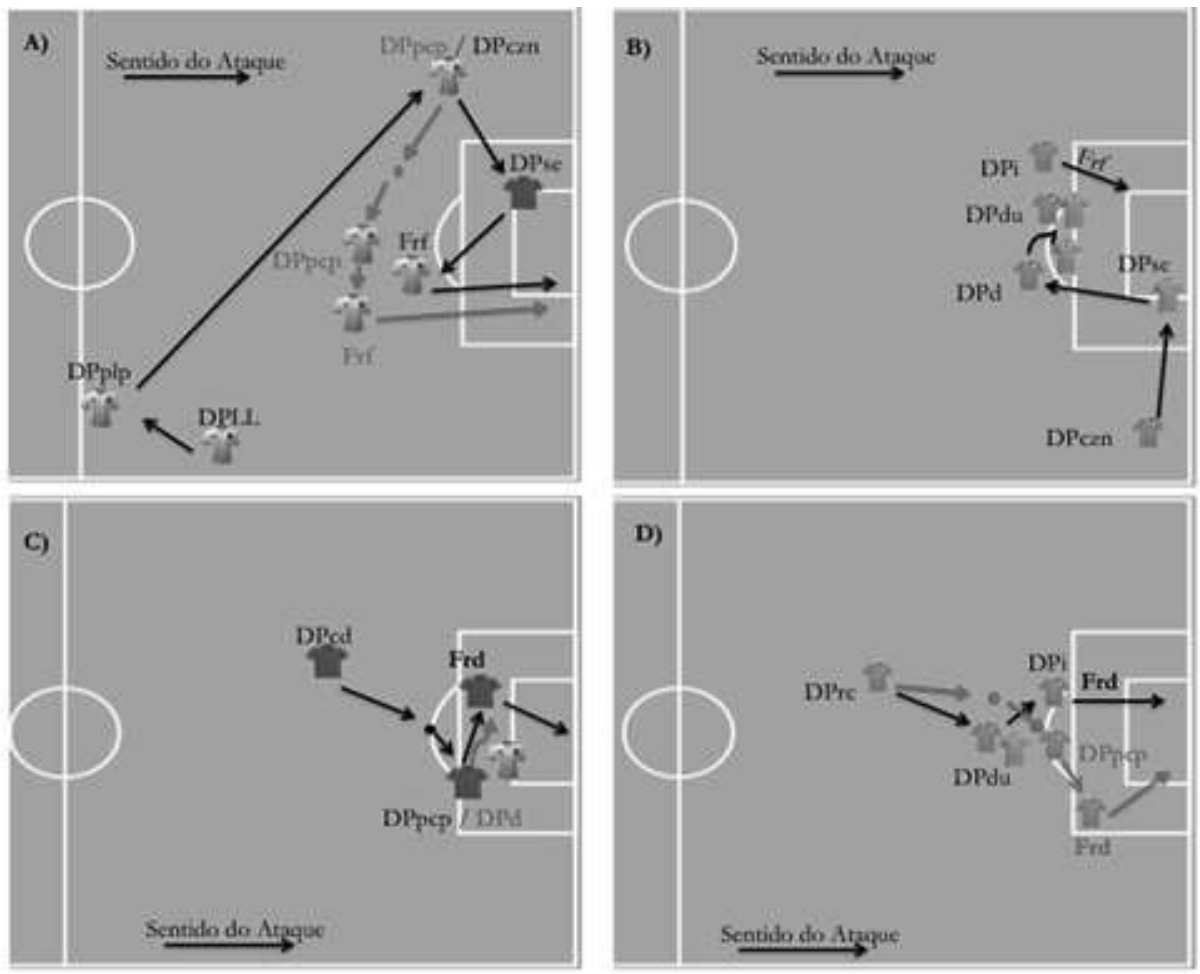

FIGURA 2 - Padrão ofensivo referente ao remate não enquadrado com a baliza adversária efetuado pela seleção da Alemanha (A) e da Holanda (B), e ao remate enquadrado com a baliza adversária efetuado pela seleção da Espanha (C) e da Holanda (D).

A seleção do Uruguai, por sua vez, tende a realizar passe curto positivo na zona lateral esquerda ofensiva $(\mathrm{z}=2,65)$ antes de efetuar o remate enquadrado com a baliza adversária. A sequência ofensiva inicia-se a partir de um pontapé de baliza $(\mathrm{z}=3,08)$ ou de uma infração do adversário às leis do jogo $(\mathrm{z}=2,81)$, na zona lateral direita ofensiva $(\mathrm{z}=2,65)$.

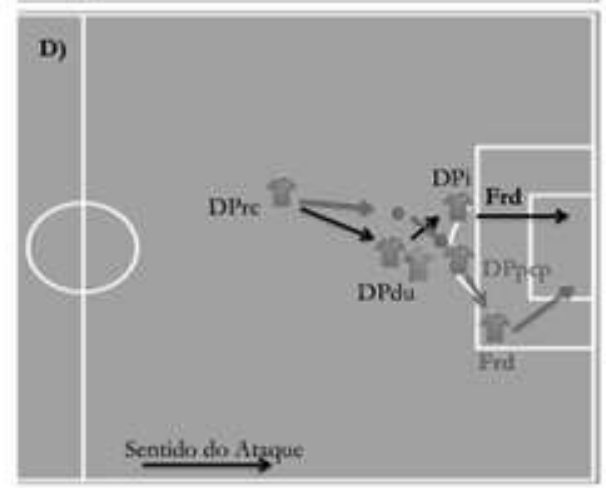

confronto entre a sua linha média e a atrasada da equipe adversária $(z=3,22)$, sendo o remate provavelmente precedido por passe curto positivo $(\mathrm{z}=$ $4,12)$ ou por drible $(\mathrm{z}=4,38)$ em desenvolvimento da posse de bola realizados na mesma zona do remate $(\mathrm{z}=3,94)$ (FIGURA 2C). Estes comportamentos tendem a ser precedidos por uma condução de bola (retardo $-3 ; \mathrm{z}=2,20$ ).

Por sua vez, a Holanda realiza o remate enquadrado com a baliza adversária em contextos de interação favoráveis no centro do jogo, i.e. em igualdade numérica sem pressão $(z=2,70)$ ou em superioridade numérica absoluta $(z=3,07)$. O remate enquadrado com a baliza adversária é frequentemente precedido por uma infração do adversário às leis do jogo $(\mathrm{z}=$ $4,20)$ ou por passe curto positivo na zona central ofensiva $(\mathrm{z}=3,60)$ em desenvolvimento da posse de bola (FIGURA 2D). 
inferioridade numérica absoluta (Espanha: $\mathrm{z}=4,18$; Uruguai: $\mathrm{z}=2,70$ ) ou relativa (Holanda: $\mathrm{z}=3,53$; Espanha: $\mathrm{z}=3,43$; Alemanha: $\mathrm{z}=2,60$ ).

Nas seleções semifinalistas do Mundial FIFA 2010, o gol tende a ocorrer na zona central ofensiva - 11 - (Alemanha: $\mathrm{z}=5,83$; Holanda: $\mathrm{z}=4,46$; Espanha: $\mathrm{z}=3,14$; Uruguai: $\mathrm{z}=2,72$ ).

A Alemanha finaliza o ataque com gol em situação de atacante "versus" goleiro adversário $(\mathrm{z}=6,26)$, sendo este contexto precedido por ação desse mesmo atacante em situação de igualdade numérica não pressionada $(\mathrm{z}=2,33)$, que decorre de um remate realizado em transição defesa/ataque $(z=3,80)$ ou de um cruzamento positivo em desenvolvimento da posse de bola $(\mathrm{z}=5,36)$ (FIGURA 3A).

No momento do gol verificam-se, para a seleção Holandesa (FIGURA 3B), situações de igualdade numérica sem pressão $(\mathrm{z}=3,24)$ e com a sua linha adiantada em confronto com a linha atrasada adversária $(z=2,59)$. Registou-se uma elevada probabilidade de os gols ocorrerem após ação do goleiro adversário em desenvolvimento da posse de bola $(z=6,28)$ e em resposta a um remate $(\mathrm{z}=6,03)$ na zona $11(\mathrm{z}=$ $5,23)$. Destaque-se que a Holanda tende a optar por comportamentos individuais de drible (retardo $-4: \mathrm{z}=$ 2,03; retardo $-3: \mathrm{z}=2,23)$ na zona $11(\mathrm{z}=4,69)$ antes de procurar finalizar. Foram também detectados padrões de gol a partir de remates em Transição-Estado defesa/ataque $(z=8,89)$, e de cruzamentos $(z=5,42)$ em desenvolvimento da posse de bola.

O Uruguai finaliza o ataque com gol em situação de atacante "versus" goleiro $(z=3,02)$, após cruzamento em Transição-Estado defesa/ataque $(z=9,40)$ na zona esquerda ofensiva $(10: z=2,80)$. Verifica-se também uma forte probabilidade de os gols resultarem de drible em desenvolvimento da posse de bola $(\mathrm{z}=3,71)$, na mesma zona em que o gol ocorre (11: $z=2,68)$, como se pode observar na FIGURA 3C.

Os gols obtidos pela equipe de Espanha apresentam elevada probabilidade de serem precedidos por um drible $(\mathrm{z}=2,50)$ e por uma posterior condução de bola $(z=2,80)$ em desenvolvimento da posse de bola na zona central ofensiva $(z=2,54)$. Posteriormente à condução de bola, verifica-se novamente drible $(z=4,28)$, seguindo-se um remate $(z=8,43)$ defendido pelo goleiro adversário $(z=5,95)$, terminando o ataque com gol (FIGURA 3D).

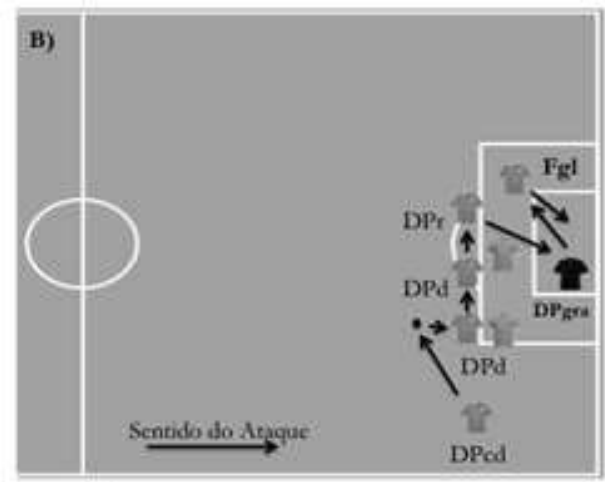

Consultar o instrumento de observação SoccerEye (TABELA1).

FIGURA 3 - Padrões ofensivos referentes à obtenção de gols pela seleção da Alemanha (A), da Holanda (B), do Uruguai (C) e da Espanha (D). 


\section{Discussão}

O presente estudo pretende caracterizar e comparar os padrōes de jogo ofensivos das equipes semifinalistas do Campeonato do Mundo FIFA 2010. Procura-se identificar as tendências de ataque que as equipes de sucesso utilizam numa competição de elite.

O elevado número de comportamentos em desenvolvimento da posse de bola realizados pelas equipes da Alemanha, Espanha e Holanda, permitiu verificar que os ataques finalizados com remates que não atingem a baliza e em que a bola sai pela linha final adversária são de longa duração. Tal constatação corrobora os resultados de HugHES e FranKs ${ }^{13}$ para os Campeonatos do Mundo Itália 1990 e Estados Unidos 1994, nos quais os autores referem que a maior frequência de remates decorre de sequências longas de passes.

Verificou-se que as seleçōes que jogaram a final do Mundial 2010 (Espanha e Holanda) utilizaram, predominantemente, um estilo de jogo indireto, mantendo a posse de bola através de comportamentos de passe e utilizando ações técnicas individuais, como o drible, para penetrar na zona defensiva adversária. Confirmam-se assim os resultados de HugHes et al. ${ }^{27}$ no Mundial 1986, no qual as equipes de sucesso apresentaram padrões ofensivos com um maior número de contactos com a bola, quando comparadas com as menos bem sucedidas. Também GRANT et al. ${ }^{11}$ referem que as equipes de sucesso no Mundial 1998 conseguiram penetrar nas defesas adversárias através de drible, condução de bola e passes de ruptura em sequências ofensivas mais longas. LUHTANEN et al. ${ }^{40}$ verificaram esta tendência no Brasil (vencedor do Campeonato do Mundo 1994), que revelou um elevado tempo de posse de bola no setor ofensivo até encontrar condições ideais para finalizar a ação ofensiva, conseguindo assim maior probabilidade de sucesso.

O Uruguai, por sua vez, revelou-se a única seleção semifinalista do Mundial 2010 que manifestou tendência para concluir o ataque com remate não enquadrado com a baliza adversária em situação de Transição-Estado defesa/ataque.

Verificaram-se diferenças relativamente à construção do ataque quando este termina com remate enquadrado com a baliza adversária: a Alemanha utiliza padrões ofensivos curtos e em transição; a Espanha recorre a um estilo indireto de ataque, adequando as suas ações ofensivas aos constrangimentos que o adversário coloca, procurando retirar proveito de espaços no corredor central; a Holanda tende a atacar preferencialmente pelo corredor central, revelando eficácia na realização de passes de ruptura facilitadores da penetração na defesa adversária; e o Uruguai conclui o ataque após infraçôes do adversário às leis do jogo, que frequentemente resultaram de comportamentos individuais.

Os remates realizados pelas equipes semifinalistas que são interceptados, com consequente perda de posse de bola, tendem a ocorrer quando o jogador portador da bola se encontra sob pressão no centro do jogo. No entanto, BARREIRA et al..$^{34}$ verificaram que esta categoria de remate tende a ocorrer em contexto de superioridade relativa no centro de jogo na segunda parte dos jogos do Campeonato do Mundo FIFA 2010, enquanto na primeira parte ocorreu uma elevada quantidade de comportamentos em desenvolvimento da posse de bola no sentido de aumentar o sucesso face a uma elevada organização defensiva adversária.

No decurso do mesmo jogo e/ou entre jogos diferentes, as seleções da Alemanha, da Espanha e do Uruguai tendem a obter gols variando o estilo de ataque (direto, com fase ofensiva em transição, ou indireto, através de fase ofensiva em desenvolvimento da posse de bola). Os cruzamentos são comportamentos utilizados pela seleção da Alemanha para penetrar na área de grande penalidade adversária, criando, desta forma, situações propícias à marcação do gol, comportamento similar ao encontrado por BARREIRA et al. ${ }^{20}$ através da análise da seleção de Espanha no Euro 2008. Durante o Mundial 2010, a equipe de Espanha evidenciou a tendência para marcar gols a partir de comportamentos coletivos (passes de ruptura e cruzamentos) desde zonas laterais ofensivas do terreno de jogo, corroborando os resultados de Grant et al. ${ }^{41}$.

Contudo, no presente estudo observaram-se também padrões ofensivos eficazes com a utilização de ações individuais, como por exemplo o Uruguai através de drible e de condução de bola para criar situações propícias ao remate, resultado justificado por SKIRKA ${ }^{42}$ quando afirma que os jogadores de equipes sul-americanas utilizam frequentemente as habilidades individuais e a velocidade para criar espaços e avançar no terreno de jogo.

Os padrões de gol da Espanha afiguram-se similares aos da Holanda, dado que ocorrem com elevada frequência após intervenção dos goleiros em fase defensiva. Estes resultados confirmam os de BARREIRA et al. ${ }^{20}$ para o Euro 2008, e de GRANT et al. ${ }^{41}$ para o Mundial França 1998 quando verificaram que em 
$54 \%$ dos gols marcados o executante recorreu apenas a um contacto com a bola. Já Silva et al. ${ }^{43}$, no estudo da fase ofensiva no Mundial Coreia-Japão 2002, observaram que os comportamentos referentes ao final de ataque são ativados por ações de desenvolvimento da posse de bola e/ou de transição, denotando uma maior propensão ofensiva, materializada através do remate, do drible ou do cruzamento, resultados similares ao encontrado no presente estudo.

Verificou-se ainda que os gols marcados pela Alemanha e pelo Uruguai foram precedidos por contextos de interação "atacante versus goleiro", enquanto nas seleções nacionais de Espanha e Holanda os gols ocorreram após situações de confronto entre a linha adiantada da equipe observada e a linha atrasada da equipe adversária. Estes resultados confirmam os de Silva et al. ${ }^{43}$, que encontraram contextos de interação eminentemente ofensivos no final dos ataques observados. Já BARREIRA et $\mathrm{al}^{20}{ }^{20}$, verificaram que os gols marcados durante o Euro 2008 tendem a ocorrer em situaçôes de atacante "versus" goleiro.

Com base nos resultados pode-se argumentar que as seleções da Espanha e da Holanda recorrem, predominantemente, a um estilo de ataque indireto, procurando manter a posse de bola até encontrar situações propícias ao remate. O Uruguai, por sua vez, evidenciou a utilização de um estilo ofensivo direto, com ataques de pouca longevidade. Por seu turno, a seleção da Alemanha apresentou maior variabilidade quanto ao método e estilo de jogo ofensivo, através do recurso à alternância de ataques curtos/longos e diretos/indiretos.

Os comportamentos individuais, em particular o drible e a condução de bola, foram frequentemente utilizados pelas equipes de Futebol de sucesso e revelaram-se indutores de eficácia ofensiva. Os cruzamentos e os passes de ruptura ocasionaram, com elevada frequência, o desequilíbrio nas defesas adversárias, proporcionando situações de finalização.

As situações de atacante "versus" goleiro e/ou de linha avançada "versus" linha defensiva, sem pressão no centro de jogo, revelaram-se contextos de interação facilitadores da obtenção de gol. No entanto, a eficácia ofensiva observada não parece acontecer em resposta a uma determinada duração das sequências (curta ou longa) nem tampouco aos estilos de jogo utilizados (direto ou indireto). De fato, pode concluir-se que a eficácia ofensiva parece decorrer do modo como as equipes conseguem alternar métodos e estilos de jogo, gerindo o tempo e o espaço de forma a provocar surpresa nos adversários, procurando impor a sua forma de jogar.

\section{Abstract}

\section{Attacking efficacy and game pattern variability in soccer}

The present study aims to characterize and compare the attacking game-patterns performed by the semifinalist teams during the FIFA World Cup 2010 - Spain, Germany, The Netherlands and Uruguay. With the use of SoccerEye observational instrument and SoccerEye recording software (v1.0, March 2011), 1938 attacks were recorded from TV public broadcasts during 28 matches (7 per team) played by the semifinalists. SoccerEye observational instrument includes seven criteria: 1) Start of the offensive phase/Ball possession recovery; 2) Development of defense/attack Transition-State; 3) Progress of ball possession; 4) End of the offensive phase; 5) Patterns of field space position; 6) Centre of the game; and 7) Spatial patterns of teams interaction. Data analysis was performed with the use of SDIS-GSEQ software (v5.0.77, 2010). Our results showed that Spanish national team-2010 FIFA World Cup winner - tended to realize shots on target after positive short passes $(z=4.12)$ or dribbles $(z=4.38)$, both actions occurring in the central offensive zone $(z=3.94)$. Also, Spain tended to score goals due to an intervention of the opponent goalkeeper $(z=5.95)$, that is a consequence of a shot on target $(z=8.43)$. We concluded that successful attacking game-patterns performed by 2010 FIFA World Cup semi-finalists were not a direct consequence of similar attacking game-methods or styles of play, but probably were related to its variation during the match and/or between matches, according to the constraints created by the opponent.

\footnotetext{
KEY WORDS: Game-patterns; Tactical behaviour; Sequential analysis; Observational methodology; Match analysis.
} 


\section{Referências}

1. Gréhaigne J. La organización del juego en el fútbol. Barcelona: INDE; 2001.

2. Hedergott KH. Fútbol: del aprendizaje a la competición. Buenos Aires: Kapelusz; 1978.

3. Teodorescu L. Problemas de teoria e metodologia nos jogos desportivos. Lisboa: Livros Horizonte; 1984.

4. Kormelink H, Seeverens T. Match analysis and game preparation. Spring City: Reedswain; 1997.

5. Oliveira JG. Conhecimento específico em futebol: contributos para a definição de uma matriz dinâmica do processo de "ensino - aprendizagem / treino" do futebol [dissertação]. Porto(PT): Universidade do Porto, Faculdade de Desporto; 2004.

6. Velásquez R. El fútbol, factores de rendimiento para planificar su enseñanza y entrenamiento. Lects Educ Fís Deportes: Rev Digital. 2005; 89.

7. Barreira D, Garganta J. Padrão sequencial da transição defesa-ataque em jogos de futebol do Campeonato Português 2004/2005. $1^{\circ}$ Congresso Internacional de Jogos Desportivos: Olhares e Contextos da Performance da iniciação ao rendimento; 2007; Porto, Portugal. Porto: Centro de Estudos dos Jogos Desportivos, Faculdade de Desporto/Universidade do Porto; 2007.

8. Mesquita I, Farias C, Oliveira G, Pereira F. A intervenção pedagógica sobre o conteúdo do treinador de futebol. Rev Bras Educ Fís Esporte. 2009;23:25-38.

9. Hughes M, Bartlett R. The use of performance indicators in performance analysis. J Sports Sci. 2002;20:739-54.

10. Dufour W. Computer-Assisted Scouting in Soccer. In: Reilly T, Clarys J, Stibbe A, editors. Science and fotball II London E \& FN Spon; 1992. p.160-6.

11. Grant A, Williams M, Reilly T, Borrie T. Analysis of the successful and unsuccessful teams in the 1998 World Cup. Coaching. 1998;2.

12. Griffiths DW. An analysis of France and their opponents at the 1998 soccer World Cup with specific reference to playing patterns [thesis]. Cardiff (USA): University of Wales Institute Cardiff; 1999.

13. Hughes M, Franks I. Analysis of passing sequences, shots and goals in soccer. J Sports Sci. 2005;23:509-14.

14. Low D, Taylor S, Williams M. A quantitative analysis of successful and unsuccessful teams. Insight. 2002;4:32-4.

15. Scoulding A, James N, Taylor J. Passing in the soccer World Cup 2002. Int J Perfom Anal Sport. 2004;4:36-41.

16. Szwarc A. Effectiveness of Brazilian and German teams and the teams defeated by them during the 17th Fifa World Cup. Kinesiology. 2004;36:83-9.

17. Hughes M, Churchill S. Attacking profiles of successful and unsuccessful team in Copa America 2001. In: Reilly T, Cabri J, Araújo D, editors. Science and football V. London: Routledge; 2005. p.219-24.

18. Nevill A, Atkinson G, Hughes M. Twenty-five years of sport performance research in the Journal of Sports Sciences. J Sports Sci. 2008;26:413-26.

19. Castellano J, Hernández Mendo A. Análisis secuencial en el fútbol de rendimiento. Psicothema. 1999;12:117-21.

20. Barreira D, Garganta J, Anguera MT. In search of nexus between attacking game-patterns, momentaneous score and type of ball recovery in European Soccer Championship 2008. In: Hughes M, Dancs H, Nagyváradi K, et al., organizers. Research methods and performance analysis. Szombately: University of West Hungary, Institute of Sport Science; 2011. p.226-37.

21. Barreira D, Garganta J, Anguera MT. Ball recovery patterns in Soccer World Cup 2010. Rev Port Ciênc Desporto. 2011;11:38-9.

22. Castellano J. Observación y análisis de la acción de juego en el fútbol [tesis]. Leoia(Bizkaia): Universidad del País Vasco; 2000.

23. Castellano J, Hernández Mendo A. El análisis de coordenadas polares para la estimación de relaciones en la interacción motriz en fútbol. Psicothema. 2003;15:569-74.

24. Lago C, Acero R. Análisis de variables determinantes en el Fútbol de alto rendimiento: el tiempo de posesión del balón (abriendo la caja negra del fútbol). Rev Entren Deport. 2005;2:12-20.

25. Lago C, Anguera MT. Evaluación y análisis del rendimiento en el fútbol: aplicaciones de la metodología observacional. Metodol Cienc Comport. 2002;Especial:327-30.

26. Anguera MT. Metodología de la observación en las ciencias humanas. Madrid: Ediciones Cátedra; 1992.

27. Hughes M, Robertson K, Nicholson A. Comparison of patterns of play of successful and unsuccessful teams in the 1986 World Cup for soccer. . In: Reilly T, Lees A, Davids K, Murphy WJ, organizers. Science and football. Liverpool: E \& FN Spon; 1988. p.363-7.

28. Borrie T, Jonsson GK, Magnusson MS. Temporal pattern analysis and its applicability in sport: an explanation and exemplar data. J Sports Sci. 2002;20:845-52. 
29. Anguera MT, Blanco A, Hernández Mendo A, Losada JL. Diseños observacionales: ajuste y aplicación en psicología del deporte. Cuad Psicol Deporte. 2011;11:63-76.

30. Anguera MT, Blanco A, Losada JL. Diseños observacionales, cuestión clave en el proceso de la metodología observacional. Metodol Cienc Comport. 2001;3:135-60.

31. Barreira D, Garganta J, Guimarães P, Machado JC, Anguera MT. Ball recovery patterns as a performance indicator in elite soccer. Proc IMechE Part P: J Sports Engineering and Technology, 2013; Epub 2013 July 15. doi: 10.1177/1754337113493083.

32. Anguera MT. Introducción. In: Anguera MT, organizadora. Metodología observacional en la investigación psicológica. Barcelona: PPU; 1991. p.25-8.

33. Gréhaigne J, Bouthier D, Godbout P. Performance assessment in team sports. J Teach Phys Educ. 1997;16:500-16.

34. Barreira D, Garganta J, Castellano J, Anguera MT. SoccerEye: a software solution to observe and record behaviours in sport settings. Open Sports Sci J. 2013;6:47-55.

35. Bakeman R, Quera V. Analysing interaction: sequential analysis with SDIS and GSEQ. Cambridge: Cambridge University Press; 1995.

36. Cohen J. A coefficient of agreement for nominal scales. Educ Psychol Measur. 1960;20:37-46.

37. Bakeman R, Gottman JM. Observación de la interacción: Introducción al análisis secuencial. Madrid: Ediciones Morata; 1989.

38. Silva A. Padrões de jogo no processo ofensivo em futebol de alto rendimento: análise dos jogos da segunda fase do Campeonato do Mundo Coreia - Japão 2002 [tesis]. Madrid(Espanha): Universidade Autónoma de Madrid; 2004.

39. Sackett GP. The lag sequential analysis of contingency and cyclicity in behavioural interaction research. In: Osofsky JD, organizer. Handbook of Infant Development. New York: Wiley; 1979. p.623-49.

40. Luhtanen PH, Korhonen V, Ilkka A. A New notational analysis system with special reference to the comparison of Brazil and its opponents in the World Cup 1994. Reilly T, Bangsbo J, Hughes M, editors. Science and football III. London: E \& FN Spon; 1997. p.229-232.

41. Grant A, Williams M, Reilly T, Borrie T. Analysis of the goals scored in the 1998 World Cup. Coaching. 1998;2.

42. Skirka N. Finding meaning in the World Cup’s Results. Soccer J. 2010:63-4.

43. Silva A, Sánchez Bañuelos F, Garganta J, Anguera MT, Oliveira M, Campaniço J. Patrones de juego en el fútbol de alto rendimiento: análisis secuencial del proceso ofensivo en el Campeonato del Mundo Corea-Japón 2002. Cult Cienc Deporte. 2005;1:65-72.

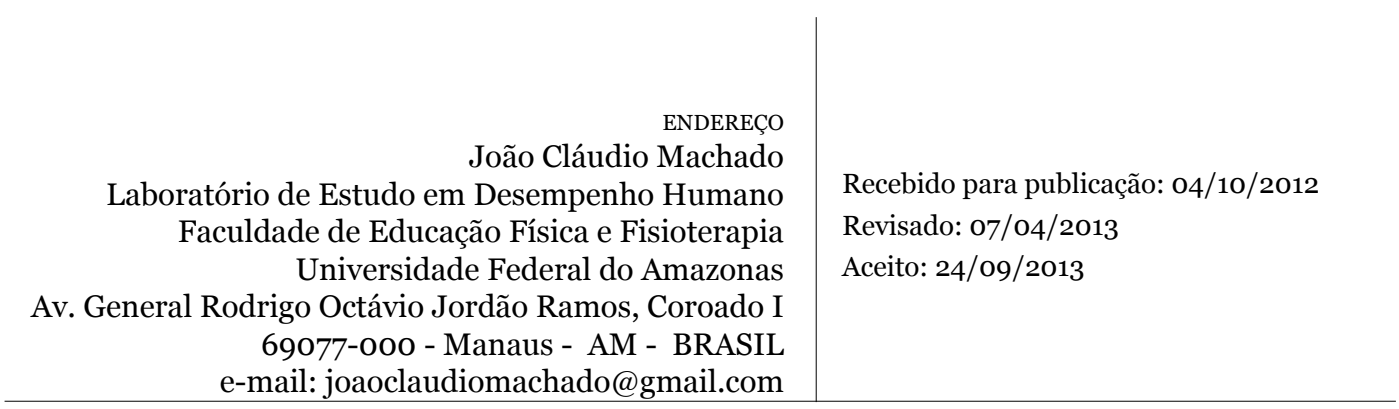

